\title{
Аополнительное
} профессиональное образование на кафецре инфекционных болезней Южно-Уральского госуАарственного

\section{медицинского университета}

\author{
Ратникова А.И., \\ Шип C.A.
}

\begin{abstract}
Федеральное государственное бюАжетное образовательное учреждение высшего образования "Южно-Уральский государственный меАицинский университет" Министерства зАравоохранения Российской Федерации, 454092, г. Челябинск, Российская Федерация
\end{abstract}

В статье изложен опыт кафедры инфекционных болезней Южно-Уральского государственного медицинского университета по использованию дополнительных профессиональных программ повышения квалификации врачей в рамках непрерывного медицинского и профессионального образования.

Цель работы - анализ дистанционно реализуемой системы дополнительного профессионального образования по проблемам инфекционных болезней.

Материал и методы. Учебные планы дополнительного профессионального образования, контрольноизмерительные материалы. Результаты прохождения повышения квалификации в течение 2019 г. в системе непрерывного медицинского образования на кафедре инфекционных болезней ФГБОУ ВО ЮУГмУ Минздрава России с последующей статистической обработкой. Рассчитан экстенсивный показатель.

Результаты и обсуждение. На примере реализованной на кафедре в 2019 г. программы повышения квалификации по теме «Дифференциальная диагностика инфекционных болезней» продемонстрирована техническая и методологическая база для совершенствования педагогического процесса в системе непрерывного медицинского образования.

Заключение. В течение 2019 г. успешно в очно-заочной форме было проведено 6 циклов повышения квалификации врачей, что позволило сформировать основные трудовые функции врача в области инфекционных болезней, которые заявлены в профессиональных стандартах и востребованы практическим здравоохранением.

Финансирование. Исследование не имело спонсорской поддержки.

Конфликт интересов. Авторы заявляют об отсутствии конфликта интересов.

Вклад авторов. Концепция и дизайн исследования - Ратникова Л.И., Шип С.А.; статистическая обработка и написание текста - Шип С.А.; сбор и обработка материала - Ратникова Л.И., Шип С.А.; редактирование - Ратникова Л.И.

Для цитирования: Ратникова Л.И., Шип С.А. Дополнительное профессиональное образование на кафедре инфекционных болезней Южно-Уральского государственного медицинского университета // Инфекционные болезни: новости, мнения, обучение. 2020. T. 9, № 3. С. 126-132. DOI: https://doi.org/10.33029/2305-3496-2020-9-3-126-132

Статья поступила в редакцию 05.01.2020. Принята в печать 02.07.2020.
Ключевыте слова: врачи, дополнительное образование, медицинский университет, инфекционные болезни

Additional professional education at the Department of Infectious Diseases of the South Ural State Medical University 
The article describes the experience of the Department of Infectious Diseases of the South Ural State Medical University in implementing additional professional training programs for doctors in the framework of continuing medical education and additional professional education.

The aim - analysis of the system of additional professional education on infectious diseases that is implemented remotely.

Material and methods. Curricula of additional professional education, control and measuring materials. The results of advanced training in 2019 in the system of continuing medical education at the Department of infectious diseases OF the South Ural state medical University of the Ministry of health of the Russian Federation with subsequent statistical processing. An extensive indicator was calculated.

Results and discussion. On the example of the advanced training program implemented at the Department in 2019 on the topic "Differential diagnosis of infectious diseases", the technical and methodological basis for improving the pedagogical process is demonstrated.

Conclusion. For 2019 successfully in the correspondence were held of doctors that helped to formulate the basic job functions of a doctor in the field of infectious diseases that are stated in professional standards and practical health care.

Funding. No financial support was provided.

Conflict of interests. The authors declare that there is no conflict of interest.

Contribution. Research concept and design - Ratnikova L.I., Ship S.A.; statistical processing and text writing - Ship S.A.;

the collection and processing of the material - Ratnikova L.I., Ship S.A; editing - Ratnikova L.I.

For citation: Ratnikova L.I., Ship S.A. Additional professional education at the Department of Infectious Diseases of the South Ural State Medical University. Infektsionnye bolezni: novosti, mneniya, obuchenie [Infectious Diseases: News, Opinions, Training]. 2020; 9 (3): 126-32. D0I: https://doi.org/10.33029/2305-3496-2020-9-3-126-132 (in Russian)

Received 05.01.2020. Accepted 02.07.2020.

\section{Keywords:}

doctors, additional education, Medical University, infectious diseases
$\mathrm{P}$ азработка и реализация дополнительных профессиональных программ (ДПП) направлены на формирование компетенций, обеспечивающих трудовые функции, заявленные в профессиональных стандартах. Методологической основой дополнительного профессионального образования (ДПО) является компетентностный подход. Организациям, реализующим дополнительные программы ДП0, необходимо разрабатывать собственное обеспечение, которое будет демонстрировать реализацию компетентностного подхода, включая планирование результатов обучения (формирование компетентностных моделей), оценку уровня формирования компетенций у выпускников и т.д. [1].

Анализ состояния системы здравоохранения и специальности «Инфекционные болезни» выявил ряд нерешенных общероссийских медицинских проблем. Одним из основных направлений решения данных проблем является совершенствование системы непрерывного медицинского образования (HМO), а именно создание национальной системы аккредитации медицинских работников с использованием дистанционного модульного персонифицированного обучения врачей $[2,3]$.

Структура модели НМО по инфекционным болезням многоуровневая, она направлена на усовершенствование профессиональных компетенций, востребованных практическим здравоохранением [4].

Цель работы - анализ дистанционно реализуемой системы ДПО по проблемам инфекционных болезней.

\section{Материал и методы}

Изучали учебные планы ДПо, контрольно-измерительные материалы к конкретной теме. Анализировали результаты прохождения повышения квалификации (ПК) в течение 2019 г. в системе НМО на кафедре инфекционных болезней ФГБОУ ВО ЮуГмУ Минздрава России с последующей статистической обработкой. Рассчитан экстенсивный показатель.

Таблица 1. Перечень Аополнительных профессиональных программ повышения квалификации, реализуемых на кафеАре инфекционных болезней ФГБОУ ВО ЮУГМУ МинзАрава России в 2019 г.

\begin{tabular}{|c|c|c|c|}
\hline $\begin{array}{l}\text { Период обучения (сроки } \\
\text { реализации программы) }\end{array}$ & $\begin{array}{c}\text { Наименование программы (цикла) повышения } \\
\text { квалификации в системе НМо }\end{array}$ & $\begin{array}{c}\text { Продолжительность } \\
\text { (количество часов } \\
\text { по системе НМо) }\end{array}$ & $\begin{array}{c}\text { Форма } \\
\text { обучения }\end{array}$ \\
\hline 22.04.2019-26.04.2019 & ПК “Аифференциальная Аиагностика инфекционных болезней” & 36 & Заочная \\
\hline 13.05.2019-15.05.2019 & ПК "Трансмиссивные клещевые инфекции” & 18 & Очно-заочная \\
\hline 20.05.2019-22.05.2019 & ПК “Хронические вирусные гепатиты и циррозы” & 18 & Очно-заочная \\
\hline 09.09.2019-14.09.2019 & ПК «Гельминтозы и протозоозы в клинической практике» & 36 & Заочная \\
\hline $07.10 .2019-12.10 .2019$ & ПК «ВИЧ-инфекция в клинической практике» & 36 & Очно-заочная \\
\hline 11.11.2019-13.11.2019 & ПК «ВИЧ-инфекция в клинической практике» & 18 & Очно-заочная \\
\hline
\end{tabular}

Расшифровка аббревиатур дана в тексте. 
Таблица 2. Учебный план заочных дополнительных профессиональных программ повышения квалификации врачей в рамках непрерывного медицинского образования, тема "Аифференциальная Аиагностика инфекционных болезней" (http://www. chelsma.ru)
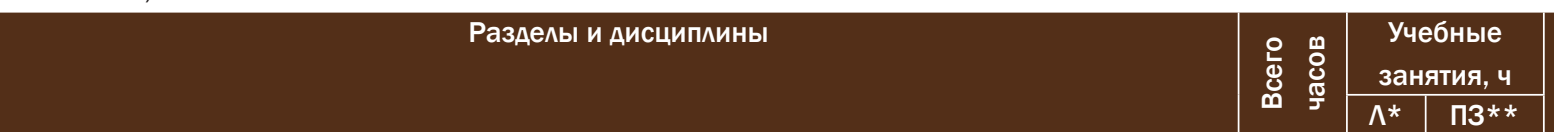

Форма

1. Аифференциальная диагностика синдрома михорадки. Классификация лихораАок. Перечень заболеваний Аля Аифференциальной Аиагностики. Клинико-Аиагностические аспекты инфекционных заболеваний, протекающих с синаромом лихорадки. Аихорадка неясного генеза. План обследования больных и тактика ведения. Эмпирическая терапия

2. Аифференциальная диагностика сыпей. Семиотика экзантем и энантем. Этиология и патогенез формирования различных морфологических элементов. Аетские инфекции, протекающие с экзантемами. Трудный больной. Клинико-диагностические аспекты инфекционных заболеваний, протекающих с синдромом сыпи. План обслеАования больных и тактика веАения 3. Определение синдрома желтухи и его классификация. Клинико-лабораторная характеристика надпеченочной, печеночной и подпеченочной желтух.

Инфекционные болезни, протекающие с синаромом желтухи. План лабораторного и инструментального обследования больных с синдромом желтухи. Аифференциальный Аиагноз заболеваний с различными виАами желтух. Аифференциальный Аиагноз вирусных гепатитов и неинфекционных заболеваний, сопровожАающихся желтухой (аутоиммунный гепатит, желтухи беременных, лекарственные поражения печени)

4. Аифференциальная Аиагностика менингеального синдрома. ОпреАеление менингеального симптомокомплекса, семиотика Аиффузного и очагового менингоэнцефалита. Классификация менингитов по этиологическим (бактериальные, вирусные, грибковые, протозойные), патогенетическим признакам (первичные, вторичные), по характеру воспалительного процесса (серозный, гнойный) Аифференциальный Аиагноз заболеваний, протекающих с менингеальным синдромом. План обследования больных с нейроинфекциями и тактика ведения. Показания и противопоказания к проведению люмбальной пункции. Современные методы исследования миквора, их Аиагностическая ценность

5. Аифференциальная Аиагностика катарально-респираторного синдрома (КРС). Семиотика КРС. Основные заболевания. Острые респираторные вирусные инфекции (ОРВИ) и острые респираторные заболевания (ОРЗ) бактериальной этиологии. Основные АифференциальноАиагностические критерии. План обследования и тактика ведения

6. Аифференциальная Аиагностика при диарее. Определение синдромов колита, гастроэнтерита, гастроэнтероколита. Перечень заболеваний Аля Аифференциальной Аиагностики. Алгоритм обследования. Степени обезвоживания при острых кишечных инфекциях (ОКИ)

7. Аифференциальная Аиагностика лимфаАенопатий. Основные изменения в периферической крови у больных мимфаденопатиями, ассоциированные с различными заболеваниями. Основные рекомендации по ведению больных лимфаденопатией. Аифференциальный Аиагноз мезаденитов

8. Аифференциальный Аиагноз синдрома тонзимлита. Перечень заболеваний Аля Аифференциальной Аиагностики. Клинико-диагностические аспекты инфекционных заболеваний, протекающих с синдромом тонзимлита. План обслеАования больных и тактика ведения. Показания к обследованию на Аифтерию

\section{Bcero}

\section{Итоговая аттестация}

Итого

Примечание. * - Л - лекции; ** - ПЗ - практические занятия.

\begin{tabular}{|c|c|c|c|}
\hline 6 & 4 & 2 & $\begin{array}{c}\text { Текущий } \\
\text { (тестовый) }\end{array}$ \\
\hline 6 & 4 & 2 & $\begin{array}{c}\text { Текущий } \\
\text { (тестовый) }\end{array}$ \\
\hline 6 & 2 & 4 & $\begin{array}{c}\text { Текущий } \\
\text { (тестовый) }\end{array}$ \\
\hline 6 & 2 & 4 & $\begin{array}{c}\text { Текущий } \\
\text { (тестовый) }\end{array}$ \\
\hline 3 & 2 & 1 & $\begin{array}{c}\text { Текущий } \\
\text { (тестовый) }\end{array}$ \\
\hline 3 & 2 & 1 & $\begin{array}{c}\text { Текущий } \\
\text { (тестовый) }\end{array}$ \\
\hline 3 & 2 & 1 & $\begin{array}{c}\text { Текущий } \\
\text { (тестовый) }\end{array}$ \\
\hline 2 & 1 & 1 & $\begin{array}{c}\text { Текущий } \\
\text { (тестовый) }\end{array}$ \\
\hline 35 & 19 & 16 & - \\
\hline 1 & - & 1 & Тестовый \\
\hline 36 & - & - & - \\
\hline
\end{tabular}

\section{Результаты и обсужхение}

Постоянно совершенствуя технические и методологические подходы, кафедра инфекционных болезней ФГБОУ В0 ЮугмУ Минздрава России уже многие годы активно разрабатывает и реализует ДПП в рамках ДПО и НМО [5-7].

Информация о перечне реализуемых на кафедре ДПП ПК в системе ДПО и НМО размещена на официальном сайте ФГБОУ ВО ЮУГМУ Минздрава России (http://www.chelsma.ru/) и на образовательном портале (http://elearning.chelsma.ru/). На сайте представлено расписание занятий в системе НMO по инфекционным болезням, которые были проведены в 2019 г., а в табл. 1 перечислены циклы повышения квалификации в системе НМО по специальности «Инфекционные болезни».

Слушатели/обучающиеся на циклах ДПП ПК - врачи различных специальностей: инфекционисты, терапевты, педиатры, врачи общей практики (семейная медицина) и др. 
Таблица 3. Информация о дополнительной профессиональной программе (АПП) повышения квалификации “Аифференциальная Аиагностика инфекционных болезней” на образовательном портале ФГБОУ ВО ЮУГМУ МинзАрава Poccuи (http://elearning. chelsma.ru)

Вид программы

По специальностям

\begin{tabular}{|l|} 
Трудоемкость \\
Режим занятий \\
Форма обучения \\
Цели
\end{tabular}

Задачи

Программа

направлена на

получение следующих

профессиональных

компетенций (ПК)

\section{Повышение квалификации (ПК)}

"Инфекционные болезни", "Лечебное Аело", "Общая врачебная практика (семейная меАицина)", "Терапия", "Педиатрия"

\section{4}

6 ч в день

Заочная (без отрыва от работы)

Совершенствование компетенций, необходимых Аля профессиональной Аеятельности в области инфектологии (Аля врачей-инфекционистов), повышение профессионального уровня в рамках имеющейся квалификации (Аля врачей смежных специальностей)

Приобретение новых профессиональных знаний, умений и навыков в Аиагностике и Аифференциальной Аиагностике инфекционных болезней, протекающих с веАущим клиническим синаромом: лихораАки, экзантемы, желтухи, Аиареи, лимфаденопатии, тонзимлита, катарально-респираторным синдромом, менингеальным синаромом

ПК-1 - готовность к реализации комплекса мероприятий, направленных на сохранение и укрепление зАоровья и включающих формирование зАорового образа жизни, предупрежАение возникновения и (или) распространения заболеваний, их раннюю диагностику, выявление причин и условий их возникновения и развития, а также направленных на устранение вредного влияния на зАоровье человека факторов среАы его обитания;

ПК-2 - готовность к провеАению профилактических медицинских осмотров, Аиспансеризации и осуществлению Аиспансерного наблюАения;

ПК-5 - готовность к опреАелению у пациентов патологических состояний, симптомов, синаромов заболеваний, нозологических форм в соответствии с Международной статистической классификацией болезней и проблем, связанных со зАоровьем;

пк-6 - готовность к веАению и лечению пациентов с инфекционными заболеваниями

\section{Требования}

к результатам освоения АПП
В результате освоения АПП обучающийся Аолжен знать:

- содержание предмета "инфекционные болезни", этиологию, эпидемиологию, патогенез инфекционных заболеваний в основных группах инфекционных болезней;

- номенклатуру и терминологию инфекционных заболеваний, международную и отечественную классификации инфекционных заболеваний;

- стандартизацию Аиагностики инфекционных заболеваний, проблемы и Аостижения;

- общеклинические лабораторные методы в инфектологии;

- иммунологические методы исследования в инфектологии;

- инструментальные методы исслеАования при кишечных инфекциях и инвазиях;

- основные симптомы и синаромы при кишечных инфекциях и инвазиях, лабораторную, эндоскопическую, морфологическую, рентгенологическую Аиагностику, Аифференциальную Аиагностику, общие принципы и методы лечения, Аиспансеризацию больных;

- эпидемиологию, этиологию, патогенез, классификации воздушно-капельных инфекций, клиническую картину, варианты начала и течения заболеваний, Аиагностику, Аифференциальную Аиагностику, общие принципы и методы мечения, Аиспансеризация больных;

- эпидемиологию, этиологию, патогенез, классификацию вирусных гепатитов, клиническую картину, варианты начала и течения заболевания, лабораторную, эндоскопическую, морфологическую Аиагностику, Аифференциальную Аиагностику, общие принципы и методы лечения, Аиспансеризацию больных;

- эпиАемиологию, этиологию, патогенез, классификации нейроинфекций, клиническую картину, варианты начала и течения заболеваний, ^абораторную, морфологическую и инструментальную Аиагностику нейроинфекций, Аифференциальную Аиагностику, общие принципы и методы лечения больных с нейроинфекциями;

- требования и правила получения информированного согласия на Аиагностические процедуры;

- методы лечения инфекционных заболеваний и их осложнений;

- методы диагностики, профилактики и комплексного лечения неотложных состояний, необходимых Аля постановки диагноза в соответствии с МежАународной статистической классификацией болезней и проблем, связанных со зАоровьем;

- законы Российской Федерации, технические регламенты, межАународные и национальные стандарты, приказы, рекоменаации; 


\section{уметь:}

-ориентироваться в вопросах нозологии, вк^ючая этиологию, патогенез и морфогенез инфекционных болезней;

- вести Аокументацию, необходимую Аля работы врача-инфекциониста;

- определить необходимость провеАения специальных методов исслеАования (лабораторных, рентгенологических, радиологических и Ар.);

- организовать их выполнение и уметь интерпретировать результаты;

- проводить Аифференциальный Аиагноз;

- оценить причину, тяжесть состояния больного и обосновать выбор комплексного лечения;

- определить объем и последовательность терапевтических и организационных мероприятий (стационарное лечение, амбулаторное лечение, консультативный прием);

- обосновать схему, план и тактику ведения инфекционного больного, показания и противопоказания к назначению этиотропных, патогенетических, симптоматических среАств, заместительной терапии; - использовать медицинскую аппаратуру, компьютерную технику в своей профессиональной Аеятельности.

\section{Практический опыт:}

- влаАеть алгоритмом Аифференциальной Аиагностики по основным клиническим синаромам; - владеть алгоритмом выполнения основных врачебных диагностических методов исследования;

- владеть навыками интерпретации результатов лабораторной и инструментальной диагностики инфекционных болезней;

- влаАеть навыками сопоставления морфологических и клинических проявлений инфекционной болезни; - владеть навыками формулировки Аиагноза;

- владеть современными методами диагностики заболеваний;

- владеть навыками терапии инфекционных заболеваний;

- влаАеть интерпретацией результатов лабораторных, инструментальных методов Аиагностики при неотложных состояниях в инфектологии;

- владеть навыками оказания помощи при неотложных состояниях в инфектологии

Всего в течение 2019 г. ДП0 на кафедре прошли 240 врачей, из них инфекционистов - 188, терапевтов - 24, педиатров - 22, фтизиатров - 6 .

В качестве примера, демонстрирующего техническую и методологическую базу реализуемых программ НM0, была выбрана ДПП ПК «Дифференциальная диагностика инфекционных болезней». На электронной странице кафедры инфекционных болезней заинтересованные в обучении по данной программе повышения квалификации могут получить дополнительную информацию, в том числе:

- о категории обучающихся (врачебные специальности, которые могут обучаться по программе повышения квалификации);

- трудоемкости и сроке освоения ДПП (18 или 36 ч);

- форме обучения (очная, очно-заочная, заочная);

- режиме занятий (ч/день);

- учебном плане;

- учебно-методическом и информационном обеспечении программы (основная и дополнительная литература, ресурсы информационно-телекоммуникационной сети Интернет);

- требованиях к итоговой аттестации;

- примере контрольно-измерительных материалов для проведения итоговой аттестации.

В учебном плане ДПП повышения квалификации представлен детализированный перечень тем лекционных и практических занятий с указанием форм контроля пройденного материала (табл. 2).
В табл. 3 представлена детальная информация о ДПП ПК «Дифференциальная диагностика инфекционных болезней», доступная для ознакомления на официальном образовательном портале ФГБОУ ВО ЮУГМУ Минздрава России (http://elearning.chelsma.ru/), в том числе:

- цели и задачи обучения;

- получаемые профессиональные компетенции;

- требования к результатам освоения ДПП в виде получаемых знаний, умений и навыков.

Освоение каждого нового раздела ДПП ПК начинается с аудиовизуальной лекции, которая в сжатой форме доводит до слушателей наиболее актуальную и сложную для восприятия информацию изучаемого раздел. С содержанием аудиовизуализированных лекций можно ознакомиться на образовательном портале ФГБОУ ВО ЮУГМУ Минздрава России (http://elearning.chelsma.ru).

После прослушивания аудиовизуальной лекции слушатели получают возможность открыть и скачать дополнительные информационные материалы к практическим занятиям по каждому из разделов ДПП ПК, включая:

- задачи для самоконтроля;

- методические указания;

- учебные материалы;

- актуальные клинические рекомендации;

- нормативно-правовую документацию и т.д.

Контроль качества приобретенных знаний, умений и владений в процессе освоения лекций и практических занятий проводится с помощью контрольно-измерительных материа- 
Таблица 4. Ведомость итоговой аттестации 51 врача, обучавшегося по программе “Аифференциальная Аиагностика инфекционных болезней" на кафедре инфекционных болезней ФГБОУ ВО ЮУГМУ Минзарава России в 2019 г.

\begin{tabular}{|c|c|c|c|c|c|}
\hline № & $\begin{array}{c}\text { ФИо } \\
\text { обучившегося }\end{array}$ & $\begin{array}{c}\text { Итоги - результаты } \\
\text { обучения }\end{array}$ & $\begin{array}{c}\text { Посещаемость, } \\
\%\end{array}$ & $\begin{array}{c}\text { Тестирование, \% } \\
\text { правильных ответов }\end{array}$ & $\begin{array}{c}\text { Тестирование, } \\
\text { оценка }\end{array}$ \\
\hline 1 & А.Ф.И. & Успешно завершил & 100 & 84 & Хорошо \\
\hline 2 & А.^.И. & Успешно завершил & 100 & 98 & Отлично \\
\hline 3 & A.A.A. & Успешно завершил & 100 & 94 & Отлично \\
\hline 4 & Б.Т.A. & Успешно завершил & 100 & 92 & Отлично \\
\hline 5 & Б.И.В. & Успешно завершил & 100 & 96 & Отлично \\
\hline$\ldots$ & $\ldots$ & $\ldots$ & $\ldots$ & $\ldots$ & $\ldots$ \\
\hline$\ldots$ & $\ldots$ & $\ldots$ & $\ldots$ & $\ldots$ & $\ldots$ \\
\hline 50 & X.E.B. & Успешно завершил & 100 & 90 & Хорошо \\
\hline 51 & Ш.A.B. & Успешно завершил & 100 & 84 & Хорошо \\
\hline
\end{tabular}

лов и итоговой аттестации. После выполнения всех тестовых заданий с последующей визуализацией в личном кабинете слушатель получает доступ к следующему этапу учебной программы. При этом важно отметить, что итоговый аттестационный тест будет доступен обучающемуся только после полного прохождения и освоения им всех разделов и подразделов тематического учебного плана.

В табл. 4 представлены итоговые результаты обучения 51 врача в системе НMO по программе «Дифференциальная диагностика инфекционных болезней».

Анализ результатов прохождения ДПО по программе ПК «Дифференциальная диагностика инфекционных болезней» показал, что в $98 \pm 1,96 \%$ случаев оценка аттестационного тестирования - «отлично» и «хорошо».

\section{Зак^ючение}

Стремясь к постоянному совершенствованию технических и методологических основ ДПО врачей, сотрудники кафедры инфекционных болезней ФГБОУ ВО ЮУГмУ Минздрава России с целью более качественной реализации компетентностного подхода в освоении инфектологии разработали систему очнозаочного дистанционного ДПО в рамках НМО по актуальным проблемам инфекционных болезней для врачей разных специальностей. В течение 2019 г. успешно в очно-заочной форме были проведены циклы ПК врачей, что позволило сформировать основные трудовые функций врача в области инфекционных болезней, которые заявлены в профессиональных стандартах и востребованы практическим здравоохранением.

\section{СВEАЕНИЯ ОБ АВТОРАХ}

Ратникова Людмила Ивановна (Lyudmila I. Ratnikova) - доктор медицинских наук, профессор, заведующая кафедрой инфекционных болезней ФГБОУ ВО ЮУГМУ Минздрава России, Челябинск, Российская Федерация

E-mail:inf23@yandex.ru

https://orcid.org/0000-0001-7373-3334

Шип Степан Александрович (Stepan A. Ship) - кандидат медицинских наук, доцент кафедры инфекционных болезней ФГБОУ ВО ЮУГмУ Минздрава России, Челябинск, Российская Федерация

E-mail: ship.stepan@mail.ru

https://orcid.org/0000-0002-8175-07051

\section{ヘИТЕРATУРA}

1. Письмо Минобрнауки России от 09.10.2013 № 06-735 "О Аополнительном профессиональном образовании".

2. Ющук Н.А., Мартынов Ю.В. Специальность «инфекционные бомезни": от анализа проблем к решениям // Инфекционные болезни: новости, мнения, обучение. 2015. № 1. С. 4-9.

3. Ющук Н.А., Мартынов Ю.В., Кухтевич Е.В. Инфектология: про блемы и актуальные перспективы развития непрерывного медицинского образования врачей // Инфекционные болезни: новости, мнения, обучение. 2013. № 1. С. 16-20.

4. Мартынов Ю.В., Кулагина М.Г. Развитие непрерывного медицинского образования по Аисциплине "инфекционные болезни" // Инфекционные болезни: новости, мнения, обучение. 2013. № 4. С. 11-14.
5. Гуревич К.Г., Зорин К.В. Педагогические новации и этические аспекты в преподавании вопросов первичной профилактики инфекционных болезней // Инфекционные болезни: новости, мнения, обучение. 2018. № 1. C. 40-45.

6. Ющук Н.А., Мартынов Ю.В. Непрерывное медицинское образование - этап подготовки к аккредитации. Итоги работы выездного заседания учебно-методической комиссии по инфекционным болезням в Сочи // Инфекционные болезни: новости, мнения, обучение. 2017. № 1. С. 9-12.

7. Ратникова А.И., Шип С.А. Расширенные видеолекции как метоА повышения эффективности непрерывного медицинского образования по специальности "инфекционные болезни" // Инфекционные болезни: новости, мнения, обучение. 2016. № 4. С. 24-28. 


\section{REFERENCES}

1. Letter of the Ministry of Education and Science of Russia dated 09.10.2013 No. 06-735 "On Additional Professional Education". (in Russian)

2. Yushchuk N.D., Martynov Yu.V. Specialty "infectious diseases»: from problem analysis to solutions. Infektsionnye bolezni: novosti, mneniya, obuchenie [Infectious Diseases: News, Opinions, Training]. 2015; (1): 4-9. (in Russian)

3. Yushchuk N.D., Martynov Yu.V., Kukhtevich E.V. Infectology: problems and current prospects for the development of continuing medical education of doctors. Infektsionnye bolezni: novosti, mneniya, obuchenie [Infectious Diseases: News, Opinions, Training]. 2013; (1): 16-20. (in Russian)

4. Martynov Yu.V., Kulagina M.G. The development of continuing medical education in the discipline "infectious diseases". Infektsionnye bolezni: novosti, mneniya, obuchenie [Infectious Diseases: News, Opinions, Training]. 2013; (4): 11-4. (in Russian)
5. Gurevich K.G., Zorin K.V. Pedagogical innovations and ethical aspects in teaching the issues of primary prevention of infectious diseases. Infektsionnye bolezni: novosti, mneniya, obuchenie [Infectious Diseases: News, Opinions, Training]. 2018; (1): 40-5. (in Russian)

6. Yushchuk N.D., Martynov Yu.V. Continuing medical education is the stage of preparation for accreditation. Results of the work of the visiting meeting of the educational and methodical commission on infectious diseases in Sochi. Infektsionnye bolezni: novosti, mneniya, obuchenie [Infectious Diseases: News, Opinions, Training]. 2017; (1): 9-12. (in Russian)

7. Ratnikova L.I., Ship S.A. Extended video lectures as a method of increasing the effectiveness of continuing medical education in the specialty "Infectious Diseases". Infektsionnye bolezni: novosti, mneniya, obuchenie [Infectious Diseases: News, Opinions, Training]. 2016; (4): 24-8. (in Russian) 